\title{
Comparison of dose-dense vs. 3-weekly paclitaxel and carboplatin in the first-line treatment of ovarian cancer in a propensity score-matched cohort
}

Rafaela Pirolli', Viviane Teixeira Loiola de Alencar', Felipe Leonardo Estati ${ }^{1}$, Adriana Regina Gonçalves Ribeiro ${ }^{1}$, Daniella Yumi Tsuji Honda', Mariana de Oliveira', Joao Paulo da Silveira Nogueira Lima', Elizabeth Santana dos Santos', Andrea Paiva Gadelha Guimarães ${ }^{1}$, Glauco Baiocchi ${ }^{2}$ and Alexandre André Balieiro Anastácio da $\operatorname{Costa}^{{ }^{*}}$ (1)

\begin{abstract}
Background: Benefit of carboplatin and dose-dense weekly paclitaxel (ddCT) in first line treatment of ovarian cancer patients has been different in Western and Asian studies. In the present study we compare progression-free survival (PFS) of ddCT to three-weekly carboplatin and paclitaxel (CT) in first-line treatment of ovarian carcinoma in a single institution in a Western population.
\end{abstract}

Materials and methods: We conducted a retrospective review of medical records from patients with ovarian carcinoma treated in a tertiary cancer center from 2007 to 2018. All patients treated with ddCT or CT in the first-line setting were included. Patients who received first-line bevacizumab were not included. PFS and overall survival (OS) were compared in a propensity score-matched cohort to address selection bias. Patients were matched according to age, ECOG performance status, CA 125, FIGO stage, residual disease, and histological subtype, in a 1:2 ratio.

Results: Five hundred eighty-eight patients were eligible for propensity score matching, the final cohort consisted of 69 patients treated with ddCT and 138 CT group. Baseline characteristics were well-balanced. After a median follow-up of 65.1 months, median PFS was 29.3 vs 20.0 months, favouring ddCT treatment $(p=$ 0.035). In the multivariate cox regression ddCT showed a $18 \%$ lower risk of progression (HR $0.82,95 \% \mathrm{Cl} 0.68-$ $0.99, p=0.04$ ). Overall survival data is immature, but suggested better outcomes for ddCT (not reached versus 78.8 months; $p=0.07$.

Conclusion: Our retrospective study has shown superior PFS of ddCT over CT regimen in first-line treatment of ovarian carcinoma in a Western population not treated with bevacizumab.

Keywords: Ovarian cancer, Dose-dense, Chemotherapy, Weekly paclitaxel, Carboplatin

\footnotetext{
* Correspondence: alexandreandredacosta@gmail.com

${ }^{1}$ Department of Medical Oncology, A.C. Camargo Cancer Center, 211

Professor Antonio Prudente Street, Liberdade, Sao Paulo, SP 01509-900, Brazil

Full list of author information is available at the end of the article
}

\section{$\triangle B M C$}

(c) The Author(s). 2021 Open Access This article is licensed under a Creative Commons Attribution 4.0 International License, which permits use, sharing, adaptation, distribution and reproduction in any medium or format, as long as you give appropriate credit to the original author(s) and the source, provide a link to the Creative Commons licence, and indicate if changes were made. The images or other third party material in this article are included in the article's Creative Commons licence, unless indicated otherwise in a credit line to the material. If material is not included in the article's Creative Commons licence and your intended use is not permitted by statutory regulation or exceeds the permitted use, you will need to obtain permission directly from the copyright holder. To view a copy of this licence, visit http://creativecommons.org/licenses/by/4.0/ The Creative Commons Public Domain Dedication waiver (http://creativecommons.org/publicdomain/zero/1.0/) applies to the data made available in this article, unless otherwise stated in a credit line to the data. 


\section{Implications for practice}

The benefit of adjuvant dose-dense weekly paclitaxel and carboplatin over the conventional 3 weekly regimen in the present study of real word experience highlights the importance to further evaluate dose-dense regimen as an option to treatment of primary ovarian cancer patients in view of the limitations of previous phase 3 trials in western population.

\section{Introduction}

Ovarian cancer is the seventh most common cancer in women, the eighth most common cause of cancer death around the world, and epithelial ovarian cancer (EOC) is the most lethal gynecologic cancer $[1,2]$. Most ovarian cancer patients are diagnosed at FIGO stage III or IV and present a 5-year relative survival rate of $30 \%$ [3].

Primary debulking surgery (PDS) followed by intravenous administration of carboplatin at an area under the curve 5-6 (AUC) and paclitaxel $175 \mathrm{mg} / \mathrm{m}^{2}$ over $3 \mathrm{~h}$ every 3 weeks for six cycles is the standard of care in advanced EOC [4]. Currently, there are at least four treatment alternatives with better overall survival (OS) results in phase III studies, which include: carboplatin and dose-dense paclitaxel regimen $[5,6]$; association of bevacizumab to carboplatin and paclitaxel, with better OS exclusively in women at high risk of progression (FIGO stage III disease with $>1 \mathrm{~cm}$ residual disease following PDS, and FIGO stage IV disease) [7, 8]; intraperitoneal chemotherapy [9-11]; and hyperthermic intraperitoneal chemotherapy (HIPEC) [12]. The latter two approaches are associated with a higher incidence of toxicity and hard to reproduce.

One large trial by the Japanese Gynecologic Oncology Group (JGOG3016) showed improvement in both progression-free survival (PFS) and OS with weekly administration of paclitaxel. In this study, 631 women with FIGO stage II-IV EOC were randomized to receive either carboplatin AUC 6 with paclitaxel $180 \mathrm{mg} / \mathrm{m}^{2}$ every 3 weeks, or carboplatin AUC 6 every 3 weeks with weekly paclitaxel $80 \mathrm{mg} / \mathrm{m}^{2}$ for up to nine cycles. Patients receiving dose-dense therapy compared with conventional treatment presented a significant improvement in PFS (28.2 vs. 17.5 months) and OS (100.5 vs. 62.2 months) $[5,6]$.

However, results from subsequent trials in the Western population, Gynecologic Oncology Group (GOG) 0262 and ICON8, did not replicate the benefit in OS to the previously reported data on survival [13, 14]. In GOG0262, 792 patients with FIGO stage II-IV EOC were randomly assigned to paclitaxel $175 \mathrm{mg} / \mathrm{m}^{2}$ and carboplatin AUC 6 every 3 weeks or weekly paclitaxel $80 \mathrm{mg} / \mathrm{m}^{2}$ with carboplatin AUC 6 every 3 weeks. Bevacizumab $15 \mathrm{mg} / \mathrm{kg}$ every 3 weeks was optional in both arms and was administered to $84 \%$ of patients. There was no difference in PFS among patients assigned to the dose-dense compared with the conventionally dosed chemotherapy group (14.7 vs 14.0 months). However, there was a difference in median PFS within the group of patients who did not receive bevacizumab in favor of the dose-dense arm (14.2 vs 10.3 months) [13]. The third phase 3 study ICON8 randomized 1566 patients with FIGO stage IC-IV EOC into 3 groups: carboplatin AUC 5 or 6 and paclitaxel $175 \mathrm{mg} / \mathrm{m}^{2}$ every 3 weeks (arm 1); carboplatin AUC 5 or 6 every 3 weeks and paclitaxel 80 $\mathrm{mg} / \mathrm{m}^{2}$ weekly (arm 2); carboplatin AUC 2 and paclitaxel $80 \mathrm{mg} / \mathrm{m}^{2}$ weekly (arm 3). There was no statistically significant difference in PFS between the standard treatment group compared to the weekly treatment groups $(17.7,20.8$ and 21.0 months respectively in arms 1,2 and 3) [14]. There are two other negative phase 3 trials evaluating weekly paclitaxel regimens, but in these studies the paclitaxel regimens and the study designs were quite different from the studies cited above $[15,16]$.

Despite the negative results, these studies have some differences and none of them had the same patient characteristics of the Japanese trial. Moreover, pharmacogenetics differences in Japanese versus Western populations could partially explain conflicting results.

In this study, we aimed to evaluate the effect of the dose-dense versus conventional regimen with carboplatin and paclitaxel, without bevacizumab, in a Brazilian population.

\section{Material and methods Patients}

This retrospective cohort study comprised all consecutive patients with epithelial ovarian, tubal or peritoneal cancer who were treated at A.C. Camargo Cancer Center from January 2007 to December 2018, and who were treated with carboplatin plus weekly (dose-dense regimen) or 3-weekly paclitaxel (conventional regimen), irrespective of the date of initial diagnosis. In the present study we followed the same methodology for clinical data collection and statistical procedures as previously described in another paper of our group [17]. To address selection bias, we performed an analysis in a propensity score-matched cohort including all patients who were treated with dose-dense regimen and matching 1:2 to patients who were treated with a conventional regimen.

The study was conducted in accordance with the Declaration of Helsinki ethical guidelines and was approved by the Research Ethics Committee of A.C. Camargo Cancer Center (REC registry ${ }^{\circ}$ 2389/17). Informed consent was waived by the the Research Ethics Committee of A.C. Camargo Cancer Center (REC registry n ${ }^{\circ} 2389$ / 17) owing to the retrospective analysis of the study. 


\section{Clinical data}

In the present study we followed the same methodology for clinical data collection as previously described in another paper of our group [17]. Briefly, clinical findings were retrieved from the medical records. Baseline characteristics included age at diagnosis, date of initial diagnosis, tumor histological subtype, International Federation of Gynecology and Obstetrics (FIGO) stage, ECOG performance status, serum CA 125, moment of debulking surgery, residual disease after debulking surgery and $B R C A 1 / 2$ germline status.

Recurrence was defined per the GCIG (Gynecological Cancer Intergroup) criteria for CA125 progression or per RECIST (Response Evaluation Criteria in Solid Tumors) for image studies obtained from the medical records. The date of the earliest event was considered for progression. PFS was defined as the interval between the date of the diagnosis and the date of first recurrence or death due to any cause. OS was defined as the interval between the date of the diagnosis and death due to any cause.

\section{Treatment}

Both study groups received carboplatin at a dose calculated to produce an AUC of 5 or $6 \mathrm{mg} / \mathrm{mL}$ per min on day 1 of a 21-day cycle. The standard group received paclitaxel given as a 3-h intravenous infusion at a dose of $175 \mathrm{mg} / \mathrm{m}^{2}$ on day 1 and in the dose-dense group, paclitaxel was administered as a 1-h intravenous infusion at a dose of $80 \mathrm{mg} / \mathrm{m}^{2}$ on days 1,8 , and 15 every 3 weeks. Patients needed to have an absolute neutrophil count of $1.0 \times 10^{9}$ cells per $\mathrm{L}$ or more and a platelet count of $75 \times 10^{9}$ per $\mathrm{L}$ or more to receive subsequent cycles of therapy in both groups. Patients in the dosedense regimen group also had to have an absolute neutrophil count of $0.5 \times 10^{9}$ cells per $\mathrm{L}$ or more and a platelet count of $50 \times 10^{9}$ per L or more before they received paclitaxel on days 8 and 15 .

The decision with regard primary or interval debulking surgery was made per surgeon with expertise in gynecologic oncology at our institution. There were no patients treated with PARP inhibitors or bevacizumab.

\section{Statistical analysis}

To overcome possible selection bias between dosedense and conventional chemotherapy regimen patients, we performed a propensity score matching (PSM) with a 1:2 ratio. The PSM overcomes the different distribution of covariates among individuals allocated to specific interventions in the study. All patients treated with dose-dense regimen were identified and each one of them was matched to 2 patients treated with the conventional regimen with the closest propensity score using greedy matching and the nearest neighbor matching approaches. The propensity score model was generated using all potential covariates that could affect the group allocation aiming to draw more reliable results. Patients were matched according to age younger or older than 65 years old, ECOG performance status of 0 or $\geq 1$, CA 125 less or more than 200, FIGO stage I-II or III-IV, primary or interval surgery, residual disease and histological subtype.

In the present study we followed the same methodology for other statistical procedures as previously described in another paper of our group [17]. Briefly, frequencies, medians and interquartile range (IQR) were used to describe patients' characteristics. The association between patients' characteristics was tested by Quisquare Test. PFS and OS curves were plotted by KaplanMeier method and we used log-rank test to test the association between clinical characteristics and survival. Hazard ratios for PFS were calculated by Cox regression analysis, variables with $p<0.2$ in the univariate analysis were included in the multivariate analysis.

The statistical analysis was performed using SPSS v. 24.0 (SPSS, Chicago, IL, US) and R program, adopting a two-tailed $p$ value $<0.05$ as statistically significant.

\section{Results}

Seven hundred and seventy-four patients with ovarian cancer were treated in our institution from 2007 to 2018. After excluding patients who were not submitted to cytoreductive surgery and who were treated with other chemotherapy regimens, 69 patients were treated with dose-dense carboplatin and paclitaxel and 519 patients were treated with 3-weekly carboplatin and paclitaxel, making a total of 588 patients eligible for propensity score matching at a 1:2 ratio. The final matched cohort consisted of all 69 patients in the dosedense group and 138 patients in the conventional chemotherapy group (Fig. 1).

For the role cohort, median age was 54.3 years old, $60.8 \%$ of patients presented ECOG performance status of zero, $83.1 \%$ of tumors were high-grade serous carcinoma, FIGO stage was I in $4.8 \%$, II in $2.4 \%$, III in $82.6 \%$ and IV in $10.1 \%$ of patients. Sixty-seven percent of patients were treated with primary debulking surgery and complete cytoreduction was achieved in $88 \%$ of patients. Twenty patients $(9.8 \%)$ presented limiting toxicity leading to dose reductions or treatment interruption, 14 (20.6\%) in the dose-dense group, and $6(4.4 \%)$ in the 3weekly group $(p<0.001)$. Eight patients $(3.9 \%)$ discontinued adjuvant chemotherapy before 6 cycles due to toxicity, $3(4.3 \%)$ in the dose-dense group and $5(3.6 \%)$ in the 3-weekly group $(p=0.870)$.

Baseline characteristics of patients in both groups are shown in Table 1. The two groups were well balanced 


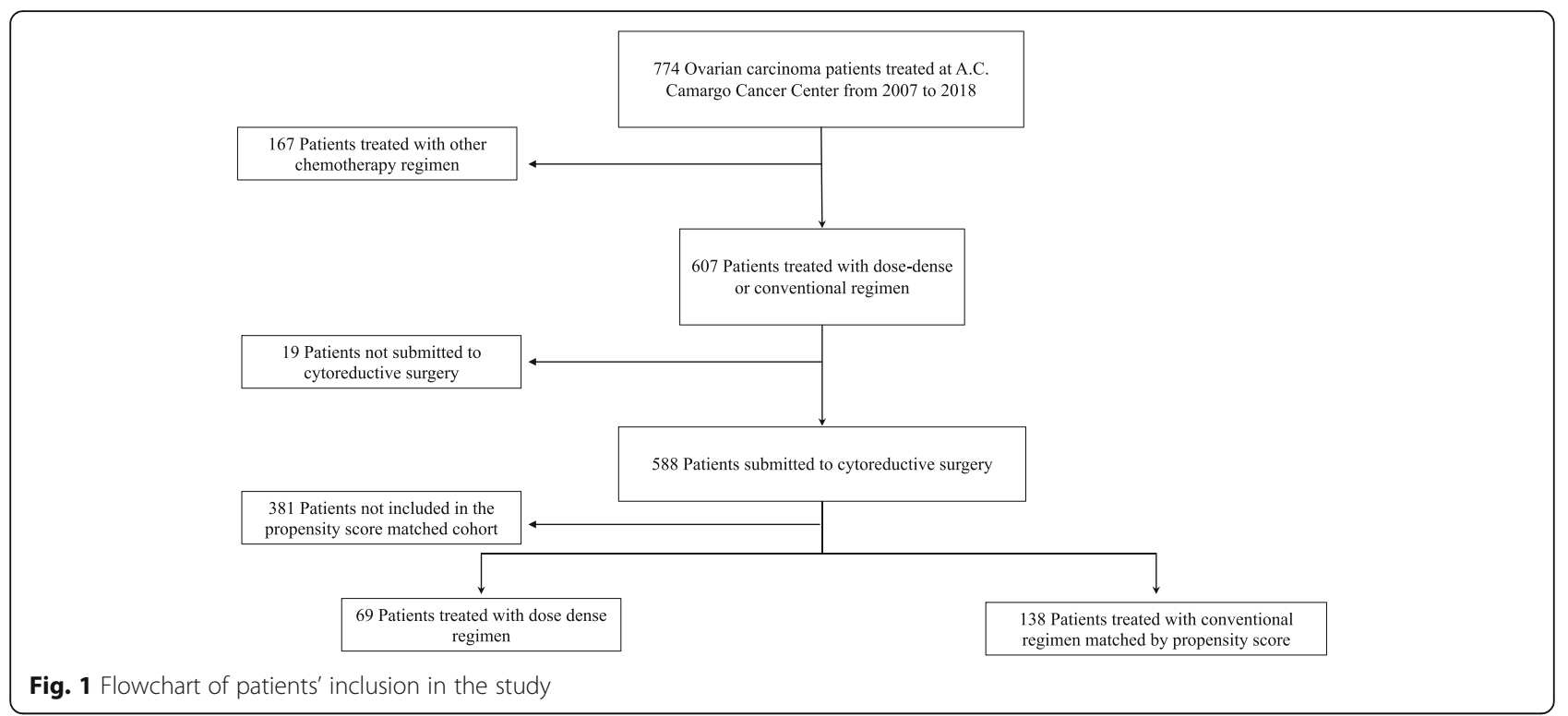

and there were no significant differences between them. Compared to patients who were treated with conventional regimen, patients treated with dose-dense protocol had a somewhat higher proportion of high-grade serous carcinoma ( $88.4 \%$ vs. $80.4 \%)$, better performance status (ECOG $065.2 \%$ vs. 57.2\%) and lower levels of CA125 (CA125 $<200$ in $42 \%$ vs. $37.7 \%$ ) but none of these differences were statistically significant. Data on BRCA1/2 mutational status was not available for a large number of patients, however, among the tested patients, the difference in the frequency of mutations between groups was not statistically significant.

For the 67 patients treated with neoadjuvant chemotherapy, data on response was available for 62 patients and the overall response rate (ORR) was $90.3 \%$. The ORR was $90.7 \%$ for the dose-dense group and $89.5 \%$ for the conventional chemotherapy group $(p=1.000)$.

\section{Progression-free survival}

After a median follow-up of 65.1 months, 154 progression events happened, and the median PFS was 23.2 months. Median PFS was longer for patients who were treated with dose-dense regimen compared to patients who were treated with conventional regimen, with 29.3 vs 20.0 months $(p=0.035)$ (Fig. 2$)$. PFS at 3 years was $40.8 \%$ vs $27.4 \%$.

In univariate analysis PFS was significantly longer in the dose-dense group ( $\mathrm{HR}=0.82 ; 95 \%$ CI $0.69-0.98 ; p=$ $0.036)$. Other variables associated with longer PFS were FIGO stage I-II, CA125 lower than 200, primary cytoreductive surgery and no residual disease after surgery. In multivariate cox regression dose-dense regimen showed a $18 \%$ lower risk of progression (HR 0.82, 95\% CI $0.68-$ 0.99, $p=0.040$ ). Interval debulking surgery (HR 1.76,
95\% CI 1.18-2.63, $p=0.005)$ and residual disease after surgery (HR 2.0, 95\% CI 1.22-3.24, $p=0.006$ ) also remained as independent prognostic factors in the final model (Table 2).

\section{Overall survival}

Eighty-one deaths happened and median OS for all patients was 83.3 months. There was no statistically significant difference in median OS between patients who were treated with dose-dense regimen compared to patients who were treated with conventional regimen, with an OS not reached vs 78.8 months, $(p=0.07)$, although longer follow-up is needed (Fig. 3). OS at 3 and 5 years were $90.4 \%$ vs 81.0 , and $74.4 \%$ vs $60.1 \%$ respectively in favor of dose-dense regimen.

\section{Subgroup analysis}

In a subgroup analysis for PFS the benefit of dose-dense regimen was homogeneous among most characteristics. Patients who presented $B R C A 1 / 2$ mutations presented a greater benefit from dose-dense than wild-type patients, as well as patients with positive family history for breast or ovarian cancer presented a greater benefit from dosedense than patients who did not have family history of breast or ovarian cancer (Fig. 4).

\section{Discussion}

Ideal first-line treatment of advanced ovarian cancer remains disputable, 3-weekly carboplatin and paclitaxel is considered the standard of care and addition of bevacizumab, use of intraperitoneal chemotherapy or dosedense paclitaxel have emerged as alternative treatment strategies [4]. Despite the OS survival benefit of dosedense schedule showed by JGOG3016, the negative 
Table 1 Baseline characteristics

\begin{tabular}{|c|c|c|c|}
\hline \multirow[t]{2}{*}{ Characteristic } & \multirow[b]{2}{*}{$\begin{array}{l}\text { Dose-dense regimen } \\
(n=69)\end{array}$} & \multicolumn{2}{|l|}{ Freq. (\%) } \\
\hline & & $\begin{array}{l}\text { Conventional regimen } \\
(n=138)\end{array}$ & $p^{a}$ \\
\hline \multicolumn{4}{|l|}{$\overline{\text { Age }}$} \\
\hline Median (P25-75) & $52.6(45.5-59.1)$ & $54.8(47.3-61.3)$ & 0.290 \\
\hline$\leq 65$ & $64(92.8)$ & $128(92.8)$ & 1.000 \\
\hline$>65$ & $5(7.2)$ & $10(7.2)$ & \\
\hline \multicolumn{4}{|l|}{ FIGO stage } \\
\hline$|-| \mid$ & $5(7.2)$ & $10(7.2)$ & 1.000 \\
\hline III-IV & $64(92.8)$ & $128(92.8)$ & \\
\hline \multicolumn{4}{|l|}{ Histology } \\
\hline High-grade serous carcinoma & $61(88.4)$ & $111(80.4)$ & 0.149 \\
\hline Others & $8(11.6)$ & $27(19.6)$ & \\
\hline \multicolumn{4}{|l|}{ ECOG performance status } \\
\hline 0 & $45(65.2)$ & $79(57.2)$ & 0.134 \\
\hline$\geq 1$ & $21(30.4)$ & $59(42.8)$ & \\
\hline Missing data & $3(4.3)$ & $0(0)$ & \\
\hline \multicolumn{4}{|l|}{ CA125 } \\
\hline Median (P25-75) & $344(72.8-1427)$ & $392.8(97-1470.2)$ & 0.614 \\
\hline$\leq 200$ & $29(42)$ & $52(37.7)$ & 0.442 \\
\hline$>200$ & $38(55.1)$ & $86(62.3)$ & \\
\hline Missing data & $2(2.9)$ & $0(0)$ & \\
\hline \multicolumn{4}{|l|}{ Type of cytoreductive surgery } \\
\hline Primary & $48(69.6)$ & $92(66.7)$ & 0.674 \\
\hline Interval & $21(30.4)$ & $46(33.3)$ & \\
\hline \multicolumn{4}{|l|}{ Complete cytoreduction } \\
\hline Yes & $61(88.4)$ & $120(87)$ & 0.570 \\
\hline No & $7(10.1)$ & $18(13)$ & \\
\hline Missing data & $1(1.4)$ & $0(0)$ & \\
\hline \multicolumn{4}{|l|}{ BRCA1/2 mutation } \\
\hline Yes & $14(20.3)$ & $11(8)$ & 0.793 \\
\hline No & $44(63.9)$ & $39(28.2)$ & \\
\hline Missing data & $11(15.9)$ & $88(63.8)$ & \\
\hline \multicolumn{4}{|c|}{ Family history of breast or ovarian cancer } \\
\hline Yes & $21(30.4)$ & $46(33.4)$ & 0.778 \\
\hline No & $43(62.4)$ & $86(62.3)$ & \\
\hline Missing data & $5(7.2)$ & $6(4.3)$ & \\
\hline
\end{tabular}

Used to compare valid data only. All $p$ values calculated by chi square test

results from GOG0262 and ICON8 put into question the benefit of dose-dense paclitaxel in Western populations $[5,6,13,14]$. In this retrospective study, we showed a longer PFS for patients who were treated with dose-dense regimen compared to patients who received conventional regimen, with PFS of 29.3 vs 20.0 months $(p=0.035)$, and $18 \%$ less risk of progression on multivariable analysis. Although OS data is still immature, there was a non-statistically significant benefit in favor of the dose-dense group (NR versus 78.8 months; $p=0.07$ ).

PFS results in the present study reproduce the results from JGOG3016 in both arms that showed median PFS of 28.2 months vs 17.5 months in favor of dose-dense regimen $[5,6]$. The median PFS of 20.0 months in the 3weekly group in our study is also similar to the 3-weekly arm from ICON8 trial [14]. Median PFS in GOG0262 


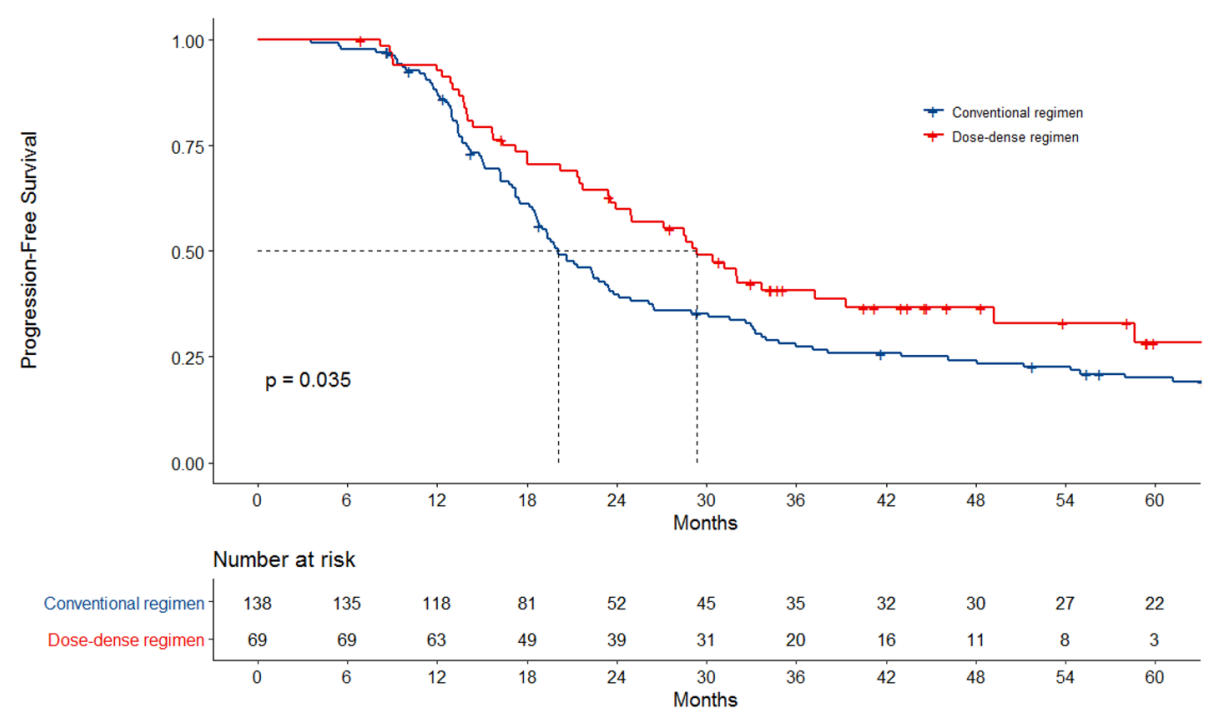

Fig. 2 Progression-free survival according to chemotherapy regimen

was shorter in both arms (14.7 months vs 14.0 months) probably related to the higher frequency of FIGO stage IV disease, which was present in $30 \%$ of patients, and the higher frequency of macroscopic residual disease after surgery, which was present in $63 \%$ of patients [13].

Patients in our study have not been treated with bevacizumab in first-line and only 30\% were treated with neoadjuvant chemotherapy. This makes our patients' characteristics and treatment schedules more similar to JGOG3016 than GOG0262 and ICON8 trials that differ from the Japanese study by the use of bevacizumab in both arms of GOG0262 and the high proportion of patients treated with neoadjuvant chemotherapy in ICON8 $[5,6,13,14]$.

A dose-dense regimen of paclitaxel involving greater frequency of drug delivery may improve its antineoplastic effect by angiogenesis inhibition and enhanced intratumoral drug perfusion $[18,19]$. This could explain why no difference in PFS was observed in GOG0262 study where only $16 \%$ of the total did not receive bevacizumab. In the subgroup of patients who did not receive bevacizumab, weekly paclitaxel was associated with longer PFS than was paclitaxel administered every 3 weeks, with $38 \%$ less risk of progression or death [13].

Weekly paclitaxel may provide dividing tumor cells with more sustained exposure to paclitaxel compared with standard doses every 3 weeks. Hence, dose-dense approach could minimize tumor regrowth between cycles and limit the emergence of chemotherapy resistant cells [19]. In ICON8 trial 50\% of patients underwent interval debulking surgery (IDS) after neoadjuvant chemotherapy. The pause of chemotherapy to proceed IDS may hamper this benefit of dose-dense schedule. Furthermore, patients selected to IDS have bulkier disease and worse prognosis and a recent study revealed that interruption of chemotherapy before and after IDS for more than 10 weeks was associated with worse prognosis [20]. Indeed, in the subgroup of patients treated with primary surgery, the survival curves do split but the study was underpowered for this subgroup analysis. In addition, there is no data on residual disease status after primary surgery, and an unbalanced distribution of residual disease status between groups may have impacted the results [14].

Two other prospective studies showed no benefit with weekly paclitaxel $[15,16]$. MITO-7 trial evaluated weekly paclitaxel at a dose of $60 \mathrm{mg} / \mathrm{m}^{2}$ and carboplatin in patients with FIGO stage IC-IV EOC and did not show a survival benefit [15]. Another trial evaluated patients with FIGO stage IIB-IV EOC and randomized them to standard 6 cycles of three weekly carboplatin and paclitaxel or a schedule consisted of paclitaxel $90 \mathrm{mg} / \mathrm{m}^{2}$ and carboplatin AUC 4 or cisplatin $70 \mathrm{mg} / \mathrm{m}^{2}$ weekly on days $1,8,15,29,36$, and 43; then there was a second randomization for three weekly carboplatin and paclitaxel for 3 versus 6 cycles. There was no survival benefit for the weekly regimen neither for extended chemotherapy [16]. Both trials used weekly paclitaxel schedules that are different from the dose-dense chemotherapy as defined in the present study and in the Japanese trial, hampering any comparison to the other studies of dosedense chemotherapy.

Molecular characteristics such as BRCA1 or BRCA2 mutational status, homologous recombination deficiency (HRD) or molecular subtypes based on gene expression signatures may impact prognosis $[21,22]$. It is possible that differences in the proportion of $B R C A 1 / 2$ mutated patients, HRD and different molecular subtypes may 
Table 2 Univariate and multivariate analysis for progression-free survival

\begin{tabular}{|c|c|c|c|c|}
\hline \multirow[t]{2}{*}{ Characteristic } & \multicolumn{2}{|l|}{ Univariate } & \multicolumn{2}{|l|}{ Multivariate } \\
\hline & $\mathrm{HR}(95 \% \mathrm{Cl})$ & $\overline{p \text { value }}$ & $\mathrm{HR}(95 \% \mathrm{Cl})$ & $p$ value \\
\hline \multicolumn{5}{|l|}{ Age at diagnosis } \\
\hline$\leq 65$ & 1 & 0.412 & & \\
\hline$>65$ & $0.76(0.40-1.45)$ & & & \\
\hline \multicolumn{5}{|l|}{ Stage } \\
\hline$|-| \mid$ & 1 & 0.042 & 1 & 0.222 \\
\hline III-IV & $2.10(1.03-4.28)$ & & $1.59(0.75-3.36)$ & \\
\hline \multicolumn{5}{|l|}{ Histology } \\
\hline High-grade serous carcinoma & 1 & 0.125 & 1 & 0.757 \\
\hline Others & $0.70(0.44-1.10)$ & & $0.92(0.57-1.51)$ & \\
\hline \multicolumn{5}{|l|}{ ECOG performance status } \\
\hline 0 & 1 & 0.089 & 1 & 0.790 \\
\hline$\geq 1$ & $1.32(0.96-1.83)$ & & $0.95(0.66-1.37)$ & \\
\hline \multicolumn{5}{|l|}{ CA 125 at diagnosis } \\
\hline$\leq 200$ & 1 & 0.046 & 1 & 0.581 \\
\hline$>200$ & $1.40(1.01-1.94)$ & & $1.10(0.78-1.56)$ & \\
\hline \multicolumn{5}{|l|}{ Type of cytoreductive surgery } \\
\hline Primary & 1 & $<0.001$ & 1 & 0.005 \\
\hline Interval & $2.02(1.44-2.82)$ & & $1.76(1.18-2.62)$ & \\
\hline \multicolumn{5}{|l|}{ Complete cytoreductive surgery } \\
\hline Yes & 1 & $<0.001$ & 1 & 0.006 \\
\hline No & $2.64(1.65-4.23)$ & & $1.99(1.22-3.24)$ & \\
\hline \multicolumn{5}{|l|}{ Chemotherapy regimen } \\
\hline Conventional & 1 & 0.036 & 1 & 0.040 \\
\hline Dose-dense & $0.83(0.69-0.99)$ & & $0.82(0.68-0.99)$ & \\
\hline \multicolumn{5}{|l|}{ BRCA1/2 mutation } \\
\hline No & 1 & 0.766 & & \\
\hline Yes & $1.08(0.66-1.82)$ & & & \\
\hline \multicolumn{5}{|c|}{ Family history of breast or ovarian cancer } \\
\hline No & 1 & 0.916 & & \\
\hline Yes & $0.98(0.70-1.38)$ & & & \\
\hline
\end{tabular}

have contributed to different results of PFS and OS observed in the trials [23]. In our study $B R C A 1 / 2$ germline mutational status was available for only $52.2 \%$ of patients and it was not related to prognosis. Interestingly patients with $B R C A 1 / 2$ mutations seemed to benefit more from the dose-dense regimen. While preclinical data would suggest BRCA1/2 mutated tumors are more resistant to paclitaxel [24] and data on antiangiogenic trials suggest that BRCA1/2 mutations and HRD did not predict antiangiogenic benefit $[25,26]$, at least one small retrospective study showed $B R C A 1 / 2$ mutations are sensitive to paclitaxel monotherapy [27]. These findings should be interpreted with caution due to the small number of patients in the subgroups, but there is scarce data in the literature addressing the association of $B R C A 1 / 2$ mutations and the benefit of dose-dense regimen. Recently, an exploratory analysis of the VELIA study showed longer PFS with a dose-dense schedule in the overall cohort and in the subgroup evaluation the benefit was restricted to patients without $B R C A 1 / 2$ mutation and non HRD [28]. Post-hoc analysis in the other dose-dense studies should help to clarify this point.

It has been suggested that the pharmacogenomics differences between Japanese and Western populations are a possible cause for differences in outcomes between JGOG3016 and other studies. Efficacy and toxicity of paclitaxel are determined by drug exposure, and genetic variations may contribute to the variability of paclitaxel 


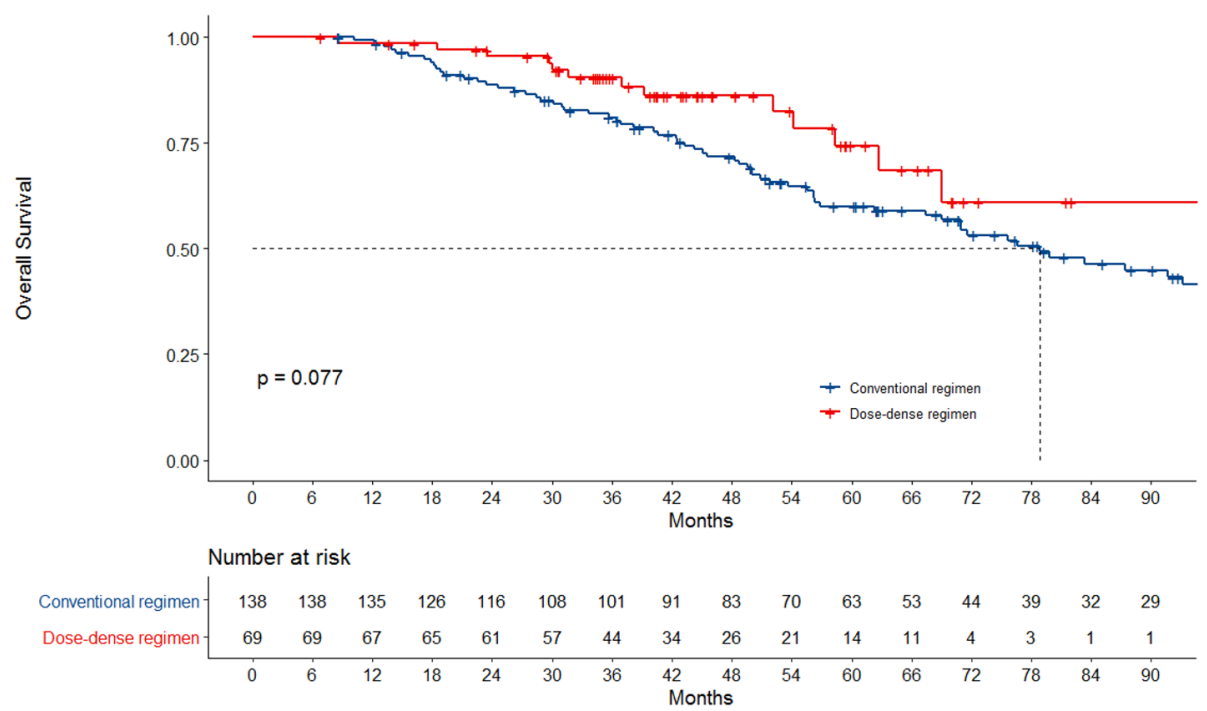

Fig. 3 Overall survival according to chemotherapy regimen

pharmacokinetics and pharmacodynamics. There are ethnic differences in polymorphisms of genes involved in the metabolism of paclitaxel, especially in CYP2C8 and CYP3A4/5 enzymes [23]. There are few data about distribution of pharmacogenetics polymorphisms among Brazilians, besides the fact that the Brazilian population is highly heterogeneous and admixed, which may cause high heterogeneity of drug responses [29]. A small study showed that the frequency of CYP2C8*2, for example, is similar to other registries, being more common in Brazilian black population ( $13 \%$ of the sample) and rare for white and Asian Brazilians (1 and 0\%, respectively) [30].
The exact role and clinical impact of the pharmacogenetic ethnic variations have yet to be clarified, and an improved understanding about this topic may eventually help to explain the conflicting results between the studies.

Limiting treatment toxicities leading to dose reductions or treatment discontinuation was less frequent than expected in our study, about $10 \%$, compared to the more than $30 \%$ rate of treatment discontinuation before 6 cycles in JGOG3016 and ICON8. These could be in part due to a younger patient population in our study with a median age of 54 years old compared to 63 years

\begin{tabular}{|c|c|c|c|c|c|}
\hline Subgroup & No. of patients (\%) & & Hazard Ratio & $95 \% \mathrm{Cl}$ & p value \\
\hline Total & 207 & $r-1$ & 0.83 & $0.69-0.99$ & 0.036 \\
\hline $\begin{array}{l}\text { Histology } \\
\text { High grade serous carcinoma } \\
\text { Outros }\end{array}$ & $\begin{array}{l}172 \\
35\end{array}$ & $\longmapsto$ & $\begin{array}{l}0.67 \\
0.61\end{array}$ & $\begin{array}{l}0.46-0.98 \\
0.20-1.83\end{array}$ & $\begin{array}{l}0.037 \\
0.381\end{array}$ \\
\hline $\begin{array}{l}\text { FIGO stage } \\
\text { IIIIIV } \\
\text { III-IV }\end{array}$ & $\begin{array}{l}15 \\
192\end{array}$ & 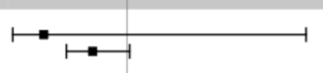 & $\begin{array}{l}0.3 \\
0.71\end{array}$ & $\begin{array}{l}0.04-2.50 \\
0.49-1.02\end{array}$ & $\begin{array}{l}0.265 \\
0.065\end{array}$ \\
\hline $\begin{array}{l}\text { Performance status } \\
001 \\
\geq 1\end{array}$ & $\begin{array}{l}124 \\
80\end{array}$ & $\mapsto$ & $\begin{array}{l}0.57 \\
0.85\end{array}$ & $\begin{array}{l}0.36-0.91 \\
0.47-1.54\end{array}$ & $\begin{array}{l}0.018 \\
0.593\end{array}$ \\
\hline $\begin{array}{r}\text { CA } 125 \\
\leq 200 \\
>200\end{array}$ & $\begin{array}{l}81 \\
124\end{array}$ & $\stackrel{\longmapsto}{\longmapsto}$ & $\begin{array}{l}0.81 \\
0.6\end{array}$ & $\begin{array}{l}0.47-1.41 \\
0.37-0.97\end{array}$ & $\begin{array}{l}0.467 \\
0.037\end{array}$ \\
\hline $\begin{array}{l}\text { Timing of surgery } \\
\text { Primary } \\
\text { Interval }\end{array}$ & $\begin{array}{l}140 \\
67\end{array}$ & $\longmapsto$ & $\begin{array}{l}0.68 \\
0.69\end{array}$ & $\begin{array}{l}0.43-1.06 \\
0.38-1.24\end{array}$ & $\begin{array}{l}0.085 \\
0.21\end{array}$ \\
\hline $\begin{array}{l}\text { Residual disease after surgery } \\
\text { Microscopic } \\
\text { Macroscopic }\end{array}$ & $\begin{array}{l}181 \\
25\end{array}$ & $\stackrel{\mapsto-1}{\mapsto}$ & $\begin{array}{l}0.8 \\
1.15\end{array}$ & $\begin{array}{l}0.66-0.97 \\
0.69-1.90\end{array}$ & $\begin{array}{l}0.024 \\
0.59\end{array}$ \\
\hline $\begin{array}{l}\text { BRCA } 1 / 2 \text { mutational status } \\
\text { Wild type } \\
\text { Mutated }\end{array}$ & $\begin{array}{l}83 \\
25\end{array}$ & $\mapsto \longmapsto 1$ & $\begin{array}{l}0.7 \\
0.31\end{array}$ & $\begin{array}{l}0.42-1.16 \\
0.12-0.86\end{array}$ & $\begin{array}{l}0.164 \\
0.024\end{array}$ \\
\hline $\begin{array}{l}\text { Family history of breast or ovarian cancer } \\
\text { No }\end{array}$ & $\begin{array}{l}129 \\
67\end{array}$ & $\mapsto \mapsto$ & $\begin{array}{l}0.78 \\
0.45\end{array}$ & $\begin{array}{l}0.50=1.21 \\
0.22-0.91\end{array}$ & $\begin{array}{l}0.277 \\
0.028\end{array}$ \\
\hline
\end{tabular}

Fig. 4 Hazard ratios for progression-free survival by baseline characteristics 
old in ICON8 and 57 years old in JGOG3016, but also could be due to a limitation of the retrospective nature of the study. Despite that, more patients in the weekly paclitaxel group presented limiting toxicity compared to the 3 -weekly regimen in our study, as in the phase 3 trials $[5,6,14]$.

The limitations of our study include its design as a retrospective study, the possibility of selection bias and the high frequency of missing data on BRCA1/2 status. We addressed these limitations using propensity score matching according to age, ECOG performance status, CA 125, FIGO stage, primary or interval surgery, residual disease, and histological subtype. This led to two groups with balanced baseline characteristics. Moreover, the benefit of dose-dense paclitaxel persisted in cox multivariate analysis. Despite that, as we conducted an observational, non-randomized study we cannot rule out the risk that the patients in our two study groups were not comparable with regard to other variables that we did not account for.

\section{Conclusion}

Our study is the first study in a Brazilian population to show the benefit of the dose-dense regimen when compared to standard 3-weekly paclitaxel, similar to JGOG3016 trial. While drug development in ovarian cancer is heading towards incorporation of new targeted drugs and immunotherapy in first-line treatment, we believe the data of ICON8 and GOG0262 do not offer enough evidence to rule out dose-dense chemotherapy as an adjuvant treatment option for non-Asian patients, and it should be considered as a possible backbone for new treatment regimens.

\section{Acknowledgements}

Not applicable.

\section{Disclaimers}

The authors declare that they have no conflict of interest.

\begin{abstract}
Authors' contributions
Rafaela Pirolli: methodology, investigation, data curation, formal analysis, writing - original draft; Viviane Alencar: investigation, data curation; Felipe Leonardo Estati: investigation, data curation; Daniella Yumi Tsuji Honda: investigation, data curation; Adriana Regina Gonçalves Ribeiro: investigation, data curation; Mariana de Oliveira: investigation, data curation; Andrea Paiva Gadelha Guimarães: writing - review \& editing; Elizabeth Santana dos Santos: writing - review \& editing; Joao Paulo da Silveira Nogueira Lima: writing review \& editing; Glauco Baiocchi: conceptualization, writing - review \& editing; Alexandre André Balieiro Anastácio da Costa: conceptualization, methodology, formal analysis, writing - original draft, supervision. The author(s) read and approved the final manuscript.
\end{abstract}

Funding

There was no financial support.

\section{Availability of data and materials}

The datasets used and/or analyzed during the current study are available from the corresponding author on reasonable request.

\section{Declarations}

Ethics approval and consent to participate

The study was approved by the institutional Ethics Committee (\# 2389/17). Informed consent was waived owing to the retrospective analysis of the study.

\section{Consent for publication}

Not applicable.

\section{Competing interests}

The authors declare that they have no conflict of interest.

\section{Author details}

${ }^{1}$ Department of Medical Oncology, A.C. Camargo Cancer Center, 211 Professor Antonio Prudente Street, Liberdade, Sao Paulo, SP 01509-900, Brazil. ${ }^{2}$ Department of Gynecologic Oncology, A.C. Camargo Cancer Center, 211 Professor Antonio Prudente Street, Liberdade, Sao Paulo, SP 01509-900, Brazil.

Received: 18 January 2021 Accepted: 23 April 2021

Published online: 08 May 2021

\section{References}

1. Bray F, Ferlay J, Soerjomataram I, Siegel RL, Torre LA, Jemal A. Global cancer statistics 2018: GLOBOCAN estimates of incidence and mortality worldwide for 36 cancers in 185 countries. CA Cancer J Clin. 2018;68:394-424.

2. Torre LA, Trabert B, DeSantis CE, Miller KD, Samimi G, Runowicz CD, et al. Ovarian cancer statistics, 2018. CA Cancer J Clin. 2018;68:284-96.

3. Lheureux S, Gourley C, Vergote I, Oza AM. Epithelial ovarian cancer. Lancet. 2019;393(10177):1240-53.

4. Karam A, Ledermann JA, Kim JW, Sehouli J, Lu K, Gourley C, et al. Fifth Ovarian Cancer Consensus Conference of the Gynecologic Cancer InterGroup: first-line interventions. Ann Oncol. 2017;28:711-7.

5. Katsumata N, Yasuda M, Takahashi F, Isonishi S, Jobo T, Aoki D, et al. Dosedense paclitaxel once a week in combination with carboplatin every 3 weeks for advanced ovarian cancer: a phase 3, open-label, randomised controlled trial. Lancet. 2009;374:1331-8. www.thelancet.com. https://doi. org/10.1016/50140.

6. Katsumata N, Yasuda M, Isonishi S, Takahashi F, Michimae H, Kimura E, et al. Long-term results of dose-dense paclitaxel and carboplatin versus conventional paclitaxel and carboplatin for treatment of advanced epithelial ovarian, fallopian tube, or primary peritoneal cancer (JGOG 3016): a randomised, controlled, open-label trial. Lancet Oncol. 2013;14:1020-6.

7. Oza AM, Cook AD, Pfisterer J, Embleton A, Ledermann JA, Pujade-Lauraine E, et al. Standard chemotherapy with or without bevacizumab for women with newly diagnosed ovarian cancer (ICON7): overall survival results of a phase 3 randomised trial. Lancet Oncol. 2015;16:928-36.

8. Perren TJ, Swart AM, Pfisterer J, Ledermann JA, Pujade-Lauraine E, Kristensen $G$, et al. A phase 3 trial of bevacizumab in ovarian cancer. N Engl J Med. 2011;365:2484-96

9. Markman M, Bundy BN, Alberts DS, Fowler JM, Clark-Pearson DL, Carson LF, et al. Phase III trial of standard-dose intravenous cisplatin plus paclitaxel versus moderately high-dose carboplatin followed by intravenous paclitaxel and intraperitoneal cisplatin in small-volume stage III ovarian carcinoma: an intergroup study of the gynecologic oncology group, southwestern oncology group, and eastern cooperative oncology group. J Clin Oncol. 2001;19(4):1001-7.

10. Armstrong DK, Bundy B, Wenzel L, Huang HQ, Baergen R, Lele S, et al. Intraperitoneal cisplatin and paclitaxel in ovarian cancer. N Engl J Med. 2006;354:34-43.

11. Alberts DS, Liu PY, Hannigan EV, OToole R, Williams SD, Young JA, et al. Intraperitoneal cisplatin plus intravenous cyclophosphamide versus intravenous cisplatin plus intravenous cyclophosphamide for stage III ovarian cancer. N Engl J Med. 1996;335(26):1950-5.

12. van Driel WJ, Koole SN, Sikorska K, Schagen van Leeuwen JH, Schreuder HWR, Hermans RHM, et al. Hyperthermic Intraperitoneal chemotherapy in ovarian Cancer. N Engl J Med. 2018;378:230-40.

13. Chan JK, Brady MF, Penson RT, Huang H, Birrer MJ, Walker JL, et al. Weekly vs. every-3-week paclitaxel and carboplatin for ovarian cancer. N Engl J Med. 2016;374:738-48. 
14. Clamp AR, James EC, McNeish IA, Dean A, Kim JW, O'Donnell DM, et al. Weekly dose-dense chemotherapy in first-line epithelial ovarian, fallopian tube, or primary peritoneal carcinoma treatment (ICON8): primary progression free survival analysis results from a GCIG phase 3 randomised controlled trial. Lancet. 2019;394:2084-95.

15. Pignata S, Scambia G, Katsaros D, Gallo C, Pujade-Lauraine E, de Placido S, et al. Carboplatin plus paclitaxel once a week versus every 3 weeks in patients with advanced ovarian cancer (MITO-7): a randomised, multicentre, open-label, phase 3 trial. Lancet Oncol. 2014;15:396-405.

16. van der Burg MEL, Onstenk W, Boere IA, Look M, Ottevanger PB, de Gooyer $D$, et al. Long-term results of a randomised phase III trial of weekly versus three-weekly paclitaxel/platinum induction therapy followed by standard or extended three-weekly paclitaxel/platinum in European patients with advanced epithelial ovarian cancer. Eur J Cancer. 2014;50:2592-601.

17. Estati FL, Pirolli R, de Alencar VTL, Ribeiro ARG, Formiga MN, Torrezan GT, et al. Impact of BRCA1/2 Mutations on the Efficacy of Secondary Cytoreductive Surgery. Ann Surg Oncol. 2020. https://doi.org/10.1245/s1 0434-020-09366-w. Epub ahead of print. PMID: 33221980.

18. Baird RD, Tan DSP, Kaye SB. Weekly paclitaxel in the treatment of recurrent ovarian cancer. Nat Rev Clin Oncol. 2010;7(10):575-82.

19. Marchetti P, Urien S, Cappellini GA, Ronzino G, Ficorella C. Weekly administration of paclitaxel: theoretical and clinical basis. Crit Rev Oncol Hematol. 2002;44 Suppl:S3-13.

20. Searle G, Pounds R, Phillips A, Kehoe S, Balega J, Singh K, et al. Prolonged interruption of chemotherapy in patients undergoing delayed debulking surgery for advanced high grade serous ovarian cancer is associated with a worse prognosis. Gynecol Oncol. 2020;158(1):54-8.

21. Bell D, Berchuck A, Birrer M, Chien J, Cramer DW, Dao F, et al. Integrated genomic analyses of ovarian carcinoma. Nature. 2011;474(7353):609-15.

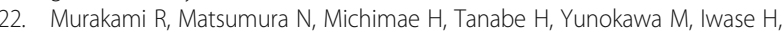
et al. The mesenchymal transition subtype more responsive to dose dense taxane chemotherapy combined with carboplatin than to conventional taxane and carboplatin chemotherapy in high grade serous ovarian carcinoma: a survey of Japanese gynecologic oncology group study (JGOG3016A1). Gynecol Oncol. 2019;153(2):312-9.

23. Lee MX, Tan DSP. Weekly versus 3-weekly paclitaxel in combination with carboplatin in advanced ovarian cancer: which is the optimal adjuvant chemotherapy regimen? J Gynecol Oncol. 2018;29:e96.

24. Hollis RL, Churchman M, Gourley C. Distinct implications of different BRCA mutations: efficacy of cytotoxic chemotherapy, PARP inhibition and clinical outcome in ovarian cancer. OncoTargets Ther. 2017;10:2539-51.

25. Norquist BM, Brady MF, Harrell MI, Walsh T, Lee MK, Gulsuner S, et al. Mutations in homologous recombination genes and outcomes in ovarian carcinoma patients in GOG 218: an NRG oncology/gynecologic oncology group study. Clin Cancer Res. 2018;24:777-83.

26. Tewari KS, Burger RA, Enserro D, Norquist BM, Swisher EM, Brady MF, et al. Final overall survival of a randomized trial of Bevacizumab for primary treatment of ovarian Cancer. J Clin Oncol. 2019;37:2317-28. https://doi.org/1 $0.1200 / J C O .19$

27. Tan DSP, Yap TA, Hutka M, Roxburgh P, Ang J, Banerjee S, et al. Implications of BRCA1 and BRCA2 mutations for the efficacy of paclitaxel monotherapy in advanced ovarian cancer. Eur J Cancer. 2013;49:1246-53.

28. Okamoto A, Fleming G, Bookman M, Brady MF, Swisher EM, Steffensen KD, et al. $818 \mathrm{P}$ Veliparib with carboplatin and paclitaxel in frontline high-grade serous ovarian cancer (HGSOC): efficacy and safety of paclitaxel weekly and every 3 weeks in the VELIA study. Ann Oncol. 2020;31:S618.

29. Suarez-Kurtz G. Pharmacogenetic testing in oncology: a Brazilian perspective. Clinics. 2018;73:e565s.

30. Kim V, van der Wal T, Nishi MY, Montenegro LR, Carrilho FJ, Hoshida Y, et al. Brazilian cohort and genes encoding for drug metabolizing enzymes and drug transporters. Pharmacogenomics. 2020;21(9):575-86.

\section{Publisher's Note}

Springer Nature remains neutral with regard to jurisdictional claims in published maps and institutional affiliations.

Ready to submit your research? Choose BMC and benefit from:

- fast, convenient online submission

- thorough peer review by experienced researchers in your field

- rapid publication on acceptance

- support for research data, including large and complex data types

- gold Open Access which fosters wider collaboration and increased citations

- maximum visibility for your research: over $100 \mathrm{M}$ website views per year

At BMC, research is always in progress.

Learn more biomedcentral.com/submissions 